\title{
The problem of interpretation in vignette methodology in research with young people
}

In this paper we explore how interpretation is dealt with by researchers using a vignette methodology. Researchers using vignette methodology often struggle with interpretation: how to interpret the responses when participants shift between discussing the vignettes as themselves, taking the perspective of the character in the vignette and commenting on what 'ought' to happen. We argue that by foregrounding a consideration of the method with an explicitly articulated theoretical position of dialogicality, issues inherent in interpretation become a valuable addition to the research rather than an obstacle to be overcome. In the paper we discuss 'Louise' a young carer, detailing the various positions she takes in her talk about the vignette of Mary, a fictitious young carer, to illustrate how a perspective based in dialogical theory contributed to the analysis of her various moves through different identity positions.

Key words: vignette methodology; dialogical self; identity

There has been a recent growth in interest in the relevance and use of vignette methodology by qualitative researchers (for example Jenkins, Bloor, Fischer, Berney and Neale, 2010; Spalding and Phillips, 2007). Vignettes have been used in a variety of research designs including questionnaire, survey and interview based work. The methodology has been used to explore a diverse range of issues in social research (for example, Brondani, MacEntee, Bryant, and O’Neil, 2008; Hughes, 1998). Vignettes are typically short stories about a fictional character or fictional scenario appropriate to a particular study. The story places the behaviour of the character in a concrete context and allows the researcher to explore participants' views on the issues arising from the situation. Vignette methodology allows researchers to systematically explore issues that could, potentially, be sensitive to research participants as it allows participants to control whether they disclose personal information or not (Barter and Reynold, 2004), and to 
discuss issues from a "non-personal and therefore less threatening perspective" (Hughes, 1998:383). There are many examples of research using this method to study potentially sensitive topics, including: research with children and young people (Barter and Reynold, 2000); an 'insider' perspective on children's perspectives on foster care (MacAuley, 1996); health issues for older people (Brondani, MacEntee, Bryant and O'Neil, 2008); and coping strategies adopted by female carers of older people (Rahman, 1996).

One key aspect for us in the recent interest in vignette methodology has been a reworking of the theoretical position of the methodology. For example, Jenkins, Bloor, Fischer, Berney and Neale (2010) drew on the work of Schutz (1967) to frame vignettes as "acts of perceptual orientation" in which participants may offer we, thou and they positions to describe and anlyse their data. These authors draw on a phenomenological position to their work. In this paper we draw on a different theoretical position to analyse vignette methodology. The position assumes that there are "multiple ways of representing reality" (Wertsch, 1991:13), which at the individual level can involve dialogues between the different positions an individual may adopt. It draws on the concept of dialogicality (Hermans, 2001; 2002; Wertsch, 1991) which argues that research must take into account the multivoicedness of people's talk, a viewpoint which is usefully applied when discussing vignette characters. Adopting this perspective it is assumed that in psychological research it is valuable to identify these multiple voices, and how they dialogue with each other, as an attempt to understand "how and why a particular voice occupies center stage, that is, why it is "privileged" (Wertsch, 1987) in a particular setting." (Wertsch, 1991: 14). This is offered in contrast to, and in critique of, the 
conventional approach in using vignette methods. It challenges two key assumptions that commonly inform researchers' use of vignette methodology - firstly that there is a singular reality and, secondly that interpretation can readily disentangle the question "who is speaking?" in the data produced by vignette methodology. These are briefly discussed below.

\section{Relationship to the 'real' and methods of interpretation}

A key assumption that is frequently made when vignettes are used in research in the social sciences is that "narrative representations of emotional events can be treated as functionally comparable to the corresponding real-life encounters" (Parkinson and Manstead, 1993:296). Thus, when working on the construction and development of vignettes, it is important to make sure the materials are meaningful and realistic for participants. This is a consideration in the design of vignettes and a key aspect of critiques of the method. Sleed et al (2002) illustrated this in their concern about the composition of vignettes:

Can such brief written narratives adequately capture the reality of the context, and thus elicit responses that would be similar to reactions to real world situations?

Some researchers who employ the method acknowledge that it cannot "fully capture the elements of reality under study" (Hughes and Huby, 2004:45) but suggest that the method is useful precisely because of the schematic nature of the material. The lack of detail in vignettes that are given to participants means that they are led to fill in the gaps which 
may reveal important data for the research project. Thus the participants' interpretation of the vignette material becomes valuable material for study rather than a weakness in the design of the research instrument.

Another assumption that is commonly made is that participants project their feelings, views and social norms onto the character in the vignette. Whilst there is a developed literature on projective testing (see for example Miller (1998) for an account of projective testing in developmental psychology), the majority of recent researchers using vignettes do not provide a theoretical account of the basis of these assumptions. They do not, for example, espouse the psychodynamic framework that has been applied to the psychological interpretation of projective responses. However, when researchers have used vignettes to attempt to study how people might behave in real life, there is an underlying cognitive theorisation which assumes a straightforward link between stated attitudes and behaviour. Different researchers have reported different findings in relation to links between stated behaviour in their vignette research and actual behaviour. For example, Rahman (1996) argued that in her work on female carers of older people their responses were very similar to what their real life responses would be. Similarly, McKeganey et al (1996) found that intravenous drug injectors were more likely to talk about sharing needles in the vignette study than in a self report study, therefore apparently giving truthful information and not responding to the vignettes in a socially desirable way. However, in a study about child protection referrals, Spratt (2001) argued that emotion played a key part in decision making in 'real life' which it was not possible to reflect in a vignette methodology. Hughes and Huby (2004) discussing Spratt's work 
suggest that the vignette methodology did not give a full context for the case/referral or in which decisions were made under high pressure as typically experienced in professional practice. It is evident that the social workers had limited knowledge of the case described in the vignette and this would have impacted upon their decisions. Vignette methodology cannot easily replicate 'real' conditions to test what would actually happen in practice. However an alternative way of framing a researcher's interpretation of participants' responses to vignette material may be to explore the dominant shared representations/ understandings of practice that are expressed and the less dominant ones that may emerge due to the personal trajectories and specific experiences of a participant (e.g. having had experience of a similar case). The focus would not then be on what participants would actually do in a specific situation, but on their subjective perceptions, feelings and experiences.

\section{Explaining diverse voices in the data: differing theoretical views}

Traditionally the focus for discussion around vignettes has been in two areas - firstly, the correspondence between participants' 'real life' behaviours and their comments on the vignettes and, secondly, whether opinions stated in the research represent a consensus view of the topic (Parkinson and Manstead, 1993; Hughes and Huby, 2004). Where results are not what were expected, some researchers have discussed the findings as indicating a problem with the methodology. One explanation is that the materials may not be written in sufficient detail and do not provide sufficient contextual information to meaningfully address the reality of the topic. Neff (1975) suggested that the more 
hypothetical vignettes appear, the less likely it is that reactions will correspond to actual behaviour. Another explanation is that participants may feel embarrassed to reveal their true feelings, relying instead upon socially accepted values and beliefs. It has been argued that vignette techniques often tap into "socially desirable patterns of responding" (Hughes and Huby, 2004:43), where participants often express less personally threatening publically accessible morality (Whittaker, 2002; Finch, 1987). In this paper we argue that a participant's view cannot be separated out from a socially sanctioned version.

Most authors who review the vignette technique point to the problems of interpretation from the viewpoint of the participant. Hughes and Huby (2004) argue that participants may give reactions to the vignettes that they think others would give rather than risk giving their own view. Hughes (1998) discusses the potential for the researcher to encounter difficulties analysing data where some participants respond as if the character is themselves whilst others respond in the third person. It seems evident that "some social stake is always involved in the version of reality that is presented" (Parkinson and Manstead, 1993:320) and that participants may choose to give a diverse range of responses to a topic, varying from their own self disclosure, to socially stigmatised views and repeating socially acceptable explanations.

There can be little doubt that vignette-based experiences are different from real-life but whether this in itself makes it an unsuitable research tool depends on the rationale for using it (Hughes, 1998:384) 
Vignette methodology can be difficult to analyse and problematic if researchers wish to disentangle the socially sanctioned, 'safe', normative interpretation of the vignette material from what participants 'really' think. Similarly, if researchers are using the method as a way of accessing what people really do in practice the method can be problematic. However, if researchers begin with a theoretical stance that assumes that individuals will be in a constant state of dialogue with the self and others, encompassing many different positions and perspectives ('voices') on anything that impinges on them, then vignettes can be used by researchers in a more productive manner. The method can provide ambiguity in the materials, to access different positions on a topic under investigation. Thus a key property of the use of vignettes in research is their flexibility. Vignettes can enable identification with socially approved view s (the 'generalised other') or the expression of agreement with normative assumptions or, in some instances, the sharing of stigmatised or self disclosed information. For researchers with an interest in exploring the range of accessible perspectives, problems of interpreting participants' voices become an asset of the methodology rather than a problematic feature of the method.

Rather than drawing on a psychodynamic or a cognitive theoretical interpretation of the data produced by a vignette methodology we argue for an interpretation drawn from theoretical insights offered by Hermans (2002). He drew on. Bakhtin's (1973) argument that monologic approaches to dialogue, that is looking purely at the words said by the individual, could not tell the whole story because the utterances are not just the creation of the self but also relate to positions and opinions given by others in relation to self. 
Therefore, singular or monologic approaches to understanding dialogue produced from a well constructed vignette cannot tell the whole story because they fail to recognize the interactional positioning which is constantly in the process of being re-created in dialogue. The work of Bakhtin has been taken up by many theorists who have developed understandings of dialogue and the relationship between socio-cultural accounts of the relationship between psychological functioning and dialogue (for example Skinner, Valsiner and Holland, 2001; Hermans, 2002, Wertsch, 1991).

Our position in relation to a theoretical and methodological orientation to research using vignettes is also informed by Hermans' (2002) view that the self functions as a "society of mind", in which the voices of the individual and collective other enter the self-space. The self in this perspective is a dynamic dialogical structure composed of a multiplicity of internal and external identifications. I-positions are voiced and engage in dialogues, which can reveal dynamics such as tension, conflict, agreement, etc. Conflicting positions can co-exist within the self, in the same way that they co-exist in society. The dominance of one position over the other (such as "I as a school child" and "I as my mother's carer") is not fixed, and can vary both over time and space.

Hermans (2001) has proposed a 'personal position repertoire' as a new methodology for studying, both qualitatively and quantitatively, "the organization and reorganization of a person's position repertoire with attention to the personal meanings that are associated with the different positions." (Hermans 2001:323). Whilst this is not the methodological approach we adopted in the research discussed in this paper, our work does draw on 
insights from Herman's theoretical work. The notion of space as a metaphor for understanding different voices and positions is important in Hermans' work where people in talk move between I-positions but also move between 'me and mine' and 'I and you', illustrating the potential for many possible internal dialogues. We were also interested in the 'matrix of internal and external positions'- that we have both internal and external positions which arise from our "person-world interactions" (Hermans 2001: 325). Internal positions can be social positions i.e. "equalized with the traditional term 'role"" (Hermans 2001: 330):

"Internal positions receive their relevance from their relation to some of the external positions. All these internal and external positions are part of the self (Ipositions) and their significance is derived from their mutual transactions over time.” (Prokopiou, 2007)

Hermans also addressed personal positions which may be in contrast to societal expectations. In addition, positions shift over time because of changes to their 'frame' (Zittoun, 2006). Aveling and Gillespie (2008:3) argue that drawing on Hermans' notion of the dialogical self "can be used to elucidate identity dynamics within a heterogeneous sociocultural context". In Aveling and Gillespie's work the identity positions of young British people of Turkish origin were outlined and various identifications such as "I as Turkish", "I as a young Turk in England" and "I as ethnic other" explored. Through this process Aveling and Gillespie could discuss the ways in which a hybridized identity of the 'young Turk' existed through various dialogical tensions which allowed or foreclosed different identifications for the young people. They argue that a focus on dialogicality 
allows them to push the notion of multiple identity identifications further to examine how they fit or fail to fit with self-identification and sociocultural context. Similarly Grossen and Salazar-Orvig (2006) discussed positions taken by participants in their focus groups. Students discussed five dilemmas of medical confidentiality and HIV infection, positioning themselves in various ways including "I think"; speaking in the name of a particular group "we think"; speaking as the character in the dilemma and generic talk. Drawing on the notion of dialogical and multiple positions of self and identity provides a very powerful analytical tool to re-think the interpretation of findings in vignette methodology, as will be illustrated in the analysis presented in this paper.

\section{Design and analysis of a vignette study}

The data drawn on in this paper form part of a larger study of childhood and what are viewed as 'atypical' roles for young people funded by the ESRC (RES-000-220549; Crafter et al, 2009). The project collected data in two phases: an initial survey of (very broadly defined) working activities of 1002 young people in two year groups at school (ages 15-16 and ages 17-18), and a second phase of in depth interviews with 46 young people identified as being either young carers, language brokers or young people who engaged in more 'typical' work roles such as having a Saturday job. Participants were recruited from six schools and colleges in the South East and South Coast of England.

The second phase of our research project used individual interviews built around four story vignettes, two depicting young people engaging in typical work roles for British 
young people such as babysitting (an informal arrangement where teenagers are paid to care for children for a few hours) and having a Saturday job (in a British context this is typically a part time weekend job) and two depicting the atypical work roles under investigation - language broker and young carer. The vignettes were designed to represent aspects of children's work that were identified by the research team to be of theoretical significance. The characters were 14 years old, slightly younger than the participants to allow them to identify with the characters and to discuss ways in which they related to the character. The vignettes were piloted with participants in a college comparable to the schools and colleges used in the project. The vignette materials were given to a group of 16-17 year old students in the pilot college. The students were asked to give feedback on the clarity, appropriateness and plausibility of the materials. The vignettes implied a variety of cultural backgrounds (indicated by culturally specific or ambiguous names such as Samuel and Mira). For example, 'Mary' a young carer:

Mary is 14 years old and lives with her dad and her brother who is 15 years old. Mary's dad is disabled and needs help during the day with activities such as getting out of bed, getting dressed and making lunch. Mary loves her dad and is happy to be there for him. However she also misses school some days if her dad has a bad day and needs extra help. Sometimes Mary wishes that she could see her friends after school like her brother does. 
There were standard questions about each vignette (such as "What advice would you give Mary if she was your friend?" and "What do you think their teacher would say?" as well as questions that involved the participant comparing the four stories (such as "Which child has the hardest job and why?", "Do you know anyone like these young people?", "Which character is most like you?"). Thus the questions were designed to encourage dialogue between various positions open to the participant including their own ideas and positions that they thought were held by key figures in their world. In this way the structuring of the questions was planned to stimulate responses that would refer to different forms of "self-identifications" (e.g. identifying with the character) and "otheridentification of the self" (e.g. how key figures such as friends and teachers would position the character).

Interviews were conducted by two of the research team in the student's school. The participants were given the opportunity to participate or withdraw from the study. A number of students were interviewed from each institution, information about the kinds of jobs performed by the participants was kept strictly confidential, and all of the interviews were conducted in the same way.

\section{Louise's positions on the young carer vignette}

Louise was an 18 year old White British young woman who cared for her disabled mother. In the following section we illustrate the various moves Louise made through positions of identification with, and making sense of, the vignette of Mary a young carer. The final section discusses the contradictions that arise from Louise's adoption of different positions. 


\section{1. "I as me" identification with the character of the vignette}

Through the vignette Louise adopts an "I as me" position in her identification with the character Mary. Here, the person-world relationship is formed through the voice of the individual in relation to the vignette character:

-What do you think about what Mary is doing?

-That's the same as me, that's the same as I did in high school, it's the same thing, you know, [...] so yeah, I understand where Mary is coming from because I've been there too. I've had a lot of experience for an eighteen year old.

The voice of the 'I' and 'me' become subsumed in a dialogical relationship. Louise's role as a carer for her mother highlights how she positions herself as identifying with the fictitious character whilst also describing a distance from other young women of her own age. This young carer's identification with the vignette character led to further discussions of experiences at school where she describes in more detail this distance between her own circumstances and those of her peers:

-I didn't fit in well with other people because when it came down to it the way I saw it was 'well I will try but they don't understand where I'm coming from so it's very hard to relate to them because I don't go through typical issues they do'. I mean, they would come on to the school going 'oh my mum's a bitch, she won't let me do this, she won't let me do that' and I'm sitting there thinking 'oh my God, how superficial are you, you don't even know what the hell you're talking about' 
Dialogical tensions described by Louise provide insight into how her own selfidentification felt at odds with the sociocultural contexts of her peers. When Louise does the talking, she speaks not only to herself and the researcher but also to the vignette character through her experiences of the past. As Aveling and Gillespie (2008) point out, it is important to know who is doing the talking and who is being talked to, as part of the dialogical process.

\section{Moving from character to self}

The multiplicity of these dialogical tensions can be seen in Louise's next quote as she moves from a consideration of Mary to a consideration of her own situation. Her shift on one level is from the position of the vignette character to the positioning of the self. Louise does this by directly comparing Mary's situation to her own and also by a more indirect elision between discussing Mary's and her own life. However, she makes a number of other positional moves within this small dialogue:

-How do you think Mary's dad might feel about the situation?

I think Mary's dad may feel a little guilty because at one point he loves his daughter but at the next point he may feel that he is taking her away from being a normal child. Or he could be like my mother and be totally consumed in the fact that he's disabled. Cos I'm there for my mother, I 
love her, but at the same time the second my mum became disabled something just flipped in her head and she changed.

She begins by reflecting on the position of the father in the story by immediately suggesting he would feel guilty, which indicates her initial positioning is with the character. However, she then uses her experiences with her own mother as a counterposition to the dialogue by returning to the self. Louise's declaration of love for her mother runs alongside her unhappiness about how she feels her mother dealt with her disability. As such, this dialogue illustrates how shifts between identifications with the character and the self are also evidenced in multiple constructions of reality that can run simultaneously. These discontinuities and contradictions expressed in the self are not unusual (Hermans, 2001). The shift in positions between the character and self can be evidenced in the next quote in a more straightforward way:

-Do you think that Mary could still be successful?

-Yeah, yeah, yeah. Mary could definitely be successful but she needs to, as I say prioritise. If she wants to be successful she's got to know that she's got to put the work in. Like I learnt at the age of sixteen, if I wanna be successful I'm gonna have to put so much effort in to make up for the years of slacking off

Here, Louise's discussions about the character are tied up with her identification of self. Louise needs the character to be successful because it is her wish that she be successful herself (evidenced in later parts of the interview). Her own experiences of "not putting 
work in" (she failed many examinations the first time she took them) are transformed as advice for Mary.

\section{I as 'you', the generalized other}

Through the person-world interactions Hermans (2001) discusses the role of internal and external positions of the self. While internal positions relate to the self, external positions acknowledge the role of the external 'other' which are part of the environment or context (such as family or teachers). The transactional nature of these internal/external positions is illustrated in the following quotes. Here Louise illustrates a generalized position using "you" to denote a shared understanding:

-What would their teacher think?

-Teachers sympathise, they do sympathise and they do try it. When it comes down to disabled parents, one thing that I found like at this college, teachers do sympathise because teachers do understand that when it comes to your family if you've got a disabled parent it is very hard on you because you have to be there for the parent but also have to get your grades. So you have the stress of school but you also have the stress of family and everything else and so teachers do understand but at the same time they don't because it's like different people react differently.

-What do you think will happen when she grows up? 
-If she, if Mary continues, cos it's difficult when you have a disabled parent because, it's true, you do have to choose what you're doing, you have to make your own choices but when it comes down to it your personality is always going to be split, [...] It doesn't matter whether you're in uni, whatever you're doing, when you've got a disabled parent of you always want to be there to help them.

The shift to "you" enables a construction of the teacher as both understanding and also not helpful. The "you" also enables the construction of the young-carer as someone who has agency and makes choices, but at the cost of living with a "split" personality (as Louise refers to it here), between the 'I' that "always want(s) to be there to help them" and the 'I' that makes choices for their own development. These choices are never made solely on the basis of internal positions but are always factored against external positions such as the "stress of family and everything else."

\section{Contradictions: shift in I positions}

Louise articulates a shared experience and understanding with Mary "that's like me" and with a broader group of young carers "if you've got a disabled parent". In doing so Louise shares her experiences and speculates about Mary's situation. However, Louise also describes her actions as different from those she advises for Mary. She reflects that her own situation is different and reflects external identifications of what others think of her. Through the interview Louise suggests Mary should attend to school regularly. However, she reflects that her own situation has been different and that it has been affected by external identifications, that others thought of her as 'dumb': 
-Like, for me, I used my, I hate to say it but I did use my mum as an excuse to get out of school because I was not having a good time and everyone thought I was dumb. But in Mary's situation she may, she may love school, she may be doing fantastic, or she may be like me and hate school and use it as an excuse. But at the same time she's still, she's still being, in a way, robbed of high school.

Here, Louise does not need to "fully capture the elements of reality" (Hughes and Huby, 2004: 45) because she plays with the subjective experience of herself in relation to the character by positioning herself as both sharing and not-sharing in the life of Mary. In this way Louise is able to use the opportunity offered her by the vignette stimulus to express a complex and multi-faceted representation of her view of the world of a young carer.

The contradictions or shifts in the I positions are not random but can be born out of the transaction between internal and external positions. In the quote below Louise's advice about getting external home help for her mother sits incongruently with her own course of action:

-Would you change anything about Mary's life?

-I would probably get more help for her because even home help helps, cos that way less burden is put on you, because you've got like somebody there who is trained to look after people and you know it's like well 'oh I don't have to take every so and so day off' 
Here, Louise takes on the dominant 'I as carer' position by presenting the fictitious character Mary with an ideal scenario. This position would also pave the way for Mary to simultaneously care and develop her own career. However, in this next quote external positions (such as home help) are characterised by Louise's I position as a "let down." Since the resources for helping her mother are not there, the position of carer she constructed for Mary did not work for her:

(...) because I decided I was gonna be my mum's carer because she got let down by a lot of her home helps so I was like "yeah, I'm gonna be her carer, I'm gonna sort this out"

There are many I positions but these may or may not be freely experienced because internal positions are always set against the restrictions of external positions. In Louise's case, if she had felt her mother's home helps had been competent this would have opened up the possibility to explore the I position she granted for Mary. As such, she could both have been a carer and have had the prospect of a career. The contradictions are not a result of Louise lying or giving false advice, but are a product of shifting perspectives. In this view of the methodology interpretation is not about checking that participants have enough information from the vignettes to make decisions; instead it is concerned with researchers having enough information from participants to document the shifts in positions discussed in response to the vignettes.

\section{Discussion}


In this paper we have used empirical work from our recent research project to argue that it is possible to encounter difficulties in how to interpret responses when participants shift between discussing the vignettes as themselves, the character and what 'ought' to happen. By considering a theoretical position that assumes poly-vocality the purpose of the method can be reinterpreted. In this paper we have illustrated how when using dialogical self theory the shifts between positions can be seen as instances of dialogue between different positions of the self, and also between internal and external positions of the self. In the data presented we have demonstrated that the methodology allows differing positions presented by participants to be documented and scrutinised. The key issue for researchers is to design the materials with appropriately structured questions that enable and facilitate the exploration of participants' voices and I-positions. The processes of vignette methodology need to address the data collection process and the social context of the research. For example, in the research presented in this paper we examined the context of young carers through a school setting. Thus the interview was designed to stimulate talk about key characters in this setting - the teacher, school friends, and as we wished to capture issues related to roles that conflict with demands from the family, the parent.

Hermans argued strongly that multivoicedness does not mean that participants do not have a stable sense of self or do not know their own minds. Rather it demonstrates the move between various legitimate social and personal positions that become relevant at different points to make sense of the topic in question. Grossen and Salazar-Orvig (2006) argue that the self is fundamentally heterogeneous (made through different voices) and 
also through systems of activity. Thus determining "who speaks" is not as self evident as it might seem (Grossen and Salazar-Orvig 2006). Wertsch (1991) argued that taking into account heterogeneity of voices requires a consideration of why particular voices take centre stage or are privileged in certain settings. The reason for emphasizing this point is that one of the issues in dialogical self theory is that only recently it started taking into account the wider social context (O’Sullivan-Lago and Abreu, 2008).

Skinner et al (2001:3) argued that "the methodology of performing any analysis of dialogical process is still in its infancy". There have been some significant contributions to addressing dialogicality. . Hermans (2001/2) has outlined a research method to document and analyse dialogicality. It produces in grid style a personal position repertoire. Aveling and Gillespie's work also offers a strong framework for the analysis of dialogical identity. Their work was based on individual and group interviews. We would argue that vignette methodology may also be used as a medium for theoretically engaged work through which to explore issues of dialogicality.

\section{References}

Crafter,S., O’Dell,L., Abreu, de.G. and Cline,T. (2009) Young people's representations of 'atypical' work in UK society. Children \& Society 23(3): 176-188

Aveling, E-L., and Gillespie, A. (2008). Negotiating multiplicity: adaptive asymmetries within second-generation Turks" "society of mind". Journal of Constructivist Psychology, 21 1-23. 
Barter, C., and Reynold, E. (2000). 'I wanna tell you a story': exploring the application of vignettes in qualitative research with children and young people. International Journal of Social Research Methodology 3(4) 307-323.

Barter, C., and Reynold, E. (2004.) The use of vignettes in qualitative research. http://www.soc.surrey.ac.uk/sru/SRU2.5html.

Brondani, M.A., MacEntee, M.I., Bryant, S.R., and O'Neil, B. (2008). Using written vignettes in focus groups among older adults to discuss oral health as a sensitive topic. Qualitative health research, 18(8) 1145-1153.

Finch, J. (1987). Research note: the vignette technique in survey research. Sociology, 21 105114.

Grossen, M and Salazar-Orvig, A. (2006). The speaker's positioning: A manifestation of the dialogicality of the self. Paper presented at the $4^{\text {th }}$ International Conference on the Dialogical Self, Braga, Portugal, (1-3 June, 2006)

Hermans, H.J.M. (2001). The construction of a personal position repertoire: Method and practice. Culture \& Psychology, 7(3) 323-366.

Hermans, H.J.M. (2002). The dialogical self as a society of mind. Theory and Psychology, 12 147-160.

Hughes,R. (1998). Considering vignette technique and its application to a study of drug injecting and HIV risk and safer behaviour. Sociology of Health and Illness, 20(3) 381400.

Hughes, R., and Huby, M. (2004). The construction and interpretation of vignettes in social research. Social Work and Social Sciences Review, 11(1) 36-51. 
Jenkins,N., Bloor,M., Fischer,J., Berney,L., and Neale,J. (2010) Putting it in to context: the use of vignettes in qualitative interviewing. Qualitative Research 10(2) 175-198

MacAuley, C. (1996) Children in Long term Foster Care: Emotional and Social Development, Hampshire: Avebury.

Mckeganey, N., Abel, M., and Hay, G. (1996). Contrasting methods of collecting data on injectors' risk behavior. AIDS Care, 8(5) 557-564.

Miller, S. A., (1998). Developmental Research Methods. ( $2^{\text {nd }}$ edition). Upper Saddle River, NJ: Prentice-Hall.

Neff, J.A. (1975). Interactional versus hypothetical others: The use of vignettes in attitude research. SSR, 64(1) 105-125.

O’Sullivan-Lago, R., and Abreu, de.G. (2009). The Dialogical Self in a Cultural Contact Zone: Exploring the Perceived 'Cultural Correction' Function of Schooling. Journal of Community \& Applied Social Psychology, 13 224-239.

O’Sullivan-Lago, R., and Abreu, de.G. (2008). Going back to their roots: Maintaining continuity in the dialogical self though signs. Psychology \& Society, 1(1) 42-53.

Parkinson, B., and Manstead, A.S.R. (1993). Making sense of emotion in stories and social life. Cognition and Emotion, 7(3/4) 295-323.

Prokopiou, E. (2007). Understanding the Impact of Greek and Pakistani Community Schools on the Development of Ethnic Minority Young Persons' Cultural and Academic Identities., Ph.D. Luton: University of Bedfordshire.

Rahman, N. (1996). Caregivers' sensitivity to conflict: The use of vignette methodology. Journal of Elder Abuse and Neglect, 8(1) 35-47. 
Skinner, D., Valsiner, J., and Holland, D. (2001). Discerning the dialogical self: A theoretical and methodological examination of a Nepali adolescent's narrative. Forum: Qualitative Social research, [online]. 2(3), Available at: http://www.qualitativeresearch.net/fqs

Sleed, M., Durrheim, K., Kreil, A., Soloman, V., and Baxter, V. (2002). The effectiveness of the vignette methodology: A comparison of written and video vignettes in eliciting responses about date rape. South African Journal of Psychology, 32(3) 21-28.

Spalding,N., and Phillips,T. (2007) Exploring the use of vignettes: from validity to trustworthiness. Qualitative Health Research 17(7) 954-962

Wertsch, J.V.(1987). Modes of discourse in the nuclear arms debate. Current research on peace and violence $10(2-3) 102-112$

Wertsch, J.V. (1991). Voices of the mind. Cambridge: Cambridge University Press.

Whittaker, A. (2002). Eliciting qualitative information about induced abortion: lessons from NorthEast Thailand. Health Care for Women International, 23 631-641.

Zittoun, T. (2006). Transitions: Development through uses of symbolic resources. Greenwich: Information Age Publishing.

\section{Biographies}

Lindsay O'Dell is Director of Post Graduate Studies for the Faculty of Health and Social Care, The Open University. Her research interests concern children and young people who are in some way 'different', including young carers, language brokers and neurodiverse children, such as those with autism.

ADDRESS: Faculty of Health and Social Care, The Open University, Walton Hall, Milton Keynes. MK7 6AA, UK

1.odell@open.ac.uk 
Dr. Sarah Crafter is a Senior Lecturer (Division of Psychology) and Research Fellow (Centre for Children and Youth) at the University of Northampton. Her research interests include home and school learning, culturally diverse childhoods, children who work, and representations of space in child and adolescent mental health services.

ADDRESS: Centre for Children and Youth \& Division of Psychology, University of Northampton, Park Campus, Northampton NN2 7AL, UK

$\underline{\text { sarah.crafter@ northampton.ac.uk }}$

Guida de Abreu is a Professor of cultural psychology at Oxford Brookes University, and Director of the Doctoral Training Programme - Children and Young People: Psychological, Educational and Health Perspectives. Her research interests focus on the impact of socio-cultural contexts in learning and identity development. Her current empirical work focuses on young people's experiences of key aspects of their lives, such as being an immigrant or minority student, acting as a language broker, acting as a young carer, and living with a chronic illness. This work includes the perspectives of teachers and parents.

ADDRESS: Psychology Department, Oxford Brookes University, Gipsy Lane Campus, Headington, Oxford, OX3 OBP, UK. gabreu@brookes.ac.uk]

Tony Cline is co-director of the part-time professional doctorate programme for experienced educational psychologists at University College London and Visiting Professor of Educational Psychology at the University of Bedfordshire. Tony initially worked in inner city and suburban areas around London as a teacher in primary and secondary schools and as an educational psychologist. After a period as Principal Educational Psychologist for the Inner London Education Authority, he moved into higher education on a full-time basis, where he has led psychology and education studies teams. His current interests include learning difficulties of bilingual pupils, selective mutism in childhood, young people's representations of child development and the analysis of the concept of school ethos.

ADDRESS: Tony Cline, Educational Psychology Group, University College London, Bedford Way, London WC1H 0AP, UK. t.cline@ucl.ac.uk 